\title{
An experimental approach to verifying prognoses of floods using an unmanned aerial vehicle
}

\author{
Matylda Witek, Justyna Jeziorska, Tomasz Niedzielski \\ University of Wroctaw, Department of Geoinformatics and Cartography, Faculty of Earth and Environmental Manage- \\ ment, Plac Uniwersytecki 1, 50-137 Wroctaw, Poland, e-mail: matylda.witek@uni.wroc.pl
}

\begin{abstract}
The Department of Geoinformatics and Cartography of the University of Wrocław, Poland, is host institution of a project, financed by the National Science Centre in Poland, whose objective is to predict riverflow in real-time. If inundation is predicted, the problem of the verification of the overbank flow prognosis arises. This verification can be attained by utilizing an unmanned aerial vehicle that may be used for remote sensing applications. The unmanned aerial vehicle in question can take sequential photos with the unprecedented resolution of $3 \mathrm{~cm} / \mathrm{pix}$. Both the resolution and the opportunity for frequent flights - due to the low cost of the entire operation - allow us to compare prediction maps showing the forecasted overbank flow during an extreme hydrological event with the true observation obtained from the air. Although such verification is site- and event-specific, it can provide us with an objective technique for checking our system in a spatial domain. The main part of the system, known as HydroProg, produces multimodel ensemble hydrograph predictions and compares single-model prognoses; visualizations of them are then published in a web map service. The spatial predictions, along with the aerial orthophoto images, will also be presented online so that the user is able to observe the functioning of the system. Regular research flights have been carried out in Kłodzko County since 2012. The study areas correspond to sites where our Partner, the County Office in Kłodzko (SW Poland) - owner of the Local System for Flood Monitoring in Kłodzko County - has automatic gauges, and thus spatially reflect the hydrologic observation network. The aforementioned aerial module is experimental and will be incorporated into the entire system.
\end{abstract}

Key words: unmanned aerial vehicle, remote sensing, fluvial processes, Kłodzko County

Submitted 22 July 2013, revised 24 January 2014, accepted 17 February 2014

\section{Introduction}

Recent hydrologic forecasting ought to be evaluated not only by the performance of given prediction methods, but its quality should in fact also be perceived as the ability to derive prognoses in an operational way. Rapid predictions - hence those that are calculated and updated in realtime every couple of hours (or even several times per hour) - need efficient algorithms, fast computational machines and reliable procedures to work in a fully automated mode. Although this automation is desirable, many hydrologic simulation or prediction techniques are still based on the knowledge offered by an expert who carries out a modelling experiment. In order to satisfy the need for the automation and correctness of the modelling process, dedicated systems and services should be built so that riverflow prognosis is available in real-time and without the significant intervention of an expert. However, such automation may introduce numerous inconsistencies in the modelling process, as within this framework the modellers are neither allowed to use their experience to enter parameters, nor are they given the opportunity to visually analyse empirical data for statistical modelling. Hence, combining multiple models, all run automatically, may serve to keep reliability at an acceptable level. Such an approach is referred to as multimodelling - this corresponds to an ensemble prediction based on models that are conceptually distinct from each other. According to Cloke and Pappenberger (2009) such an approach, along with running a single model a large number of times using Monte Carlo simulations, fits within the broad class of ensemble prediction systems (EPS). Although there are several comprehensive systems of this kind (Franz et al. 2005; Schaake et al. 2006; Butts et al. 2007; Zappa et al. 2008), such operational multimodelling experiments have not been investigated in depth in Poland. One of the first exercises in such investigation is the system powered by HydroProg (www.hydro.uni.wroc. pl), a dedicated infrastructure and service, which was built at the University of Wrocław, Poland, within the research project entitled System supporting a comparison of hydrologic predictions. The project was supported by the National Science Centre in Poland. The HydroProg experiment aims to elaborate and implement a novel system that is based in the advanced computational centre which:

(1) in real-time delivers the hydrometeorological data provided, courtesy of our partners, to participants; these participants are institutions that own models and will calculate the pointwise (at gauges) riverflow predictions in real-time,

(2) collects the prognoses for a given site computed by the participants,

(3) computes the ensemble hydrologic forecast from multiple models provided by multiple participants,

(4) provides our partners with ensemble predictions, along with individual prognoses, and then publishes them online in a dedicated web map service. 
At present, our partner is the County Office in Kłodzko (SW Poland), the owner of the Local System for Flood Monitoring in Kłodzko County. Thus, the HydroProg predictions are available in real-time for that area. Concurrently, the project's objective is to extend the study area by inviting new partners.

Intrinsic to the pointwise prediction is the problem of overbank flow that may occur in cases of certain peak flows. A flood is a spatial phenomenon. For inhabitants of areas potentially endangered by flooding, an emergency pointwise prognosis - the water level predicted at a particular water gauge - is not essentially useful. Such an alert only informs of the possibility of a danger, and does not deliver any indication of areas that may be flooded. Therefore, the scope of the project has been extended, and now the solution for the projection of pointwise riverflow prognoses into the spatial domain is being implemented. In order to deliver the information, i.e. to determine potentially endangered zones, conversion from hydrograph prognosis to inundation prediction needs to be carried out. Regardless of the inundation model used, the projection in question is conceptually difficult, particularly for larger areas, and implies a considerable degree of uncertainty in the prognoses of the spatial extent of a flood. If such a prediction scheme produces a flood warning, the problem of the verification of the overbank flow prognosis arises. Continuous information about the actual situation during the flood is needed in order to verify the accuracy of the spatial prediction of inundation. This can be attained only by remote sensors that allow for the collection of spatial information in real or near-real time.

The term unmanned aerial vehicle (UAV) covers a wide range of flying machines with the common feature of being able to take off, fly and land autonomously (i.e. with no people on board) while also being controllable in all actions from ground stations. The development of the pioneer UAV-based systems was strongly military-dependent, though the first approaches to the photogrammetric use of the UAV were undertaken by Przybilla and WesterEbbinghaus (1979). However, it took decades until the first high-resolution digital terrain model (DTM) was created using the UAV-acquired data (Eisenbeiss et al. 2005). The usability of UAVs for research purposes improved with the increasing availability of miniature Global Positioning System (GPS) solutions and Inertial Measurement Units (IMU) (Turner et al. 2012). More detailed measurements became easier to obtain due to images acquired by highresolution cameras. The great challenge now is to develop and improve photogrammetric applications, and how inaccurate data is handled is especially important in this process.

Given their ability to acquire high resolution spatial data, UAVs have become essential tools for the observation of flood inundation. Similar tasks can also be performed using LiDAR (Light Detection and Ranging) scanning (Merwade et al. 2008; Schumann et al. 2008; Sanders 2007; Bates 2004; Horritt, Bates 2002). Although the Li-
DAR survey covers a larger area, the costs of surveys and the requirement for there to be an airport nearby airport located nearby made this approach unsuitable for our experimental research.

The objective of the work presented in this paper is to discuss the potential of incorporating the UAV into the aforementioned hydrologic prediction experiment in order to test a new concept - the combining of spatial inundation prediction with its aerial verification. Since November 2012 we have been carrying out regular UAV flights in the vicinity of the selected gauges of the Local System for Flood Monitoring in Kłodzko County. Our test missions serve as a preparatory phase for the aerial segment to be used in the real-time verification of the overbank flow forecasts.

\section{Methods \\ 2.1. swinglet CAM}

swinglet CAM (Fig. 1a) is the UAV produced by the Swiss company senseFly. With a weight of only $0.5 \mathrm{~kg}$ and $80 \mathrm{~cm}$ wingspan, the manufacturer places it within the ultra-light category (Küng et al. 2011). A lithium-ion battery gives an endurance of approximately 30 minutes of flight. The on-board 12MP camera (see Fig. 1e) is integrated with the autopilot and allows it to take high resolution images with a predetermined overlap. The spatial image coverage obtained in a single flight may reach up to $10-15 \mathrm{~km}^{2}$. The swinglet CAM itself is part of a comprehensive system illustrated in Fig. 1, and the ground control station (Fig. 1b) is a laptop with dedicated software installed. The software allows for the planning and execution of a mission and guarantees full flight control due to the continuous connection between the UAV and the ground control station via a radiomodem (Fig. 1c). The artificial intelligence module incorporated into the swinglet CAM autopilot continuously analyses data, mainly from the IMU and from the on-board GPS receiver. The fully-automated UAV is hand-launched, and for safe take-off and landing a radius of at least $40 \mathrm{~m}$ from the launch position is required. In emergencies, if the

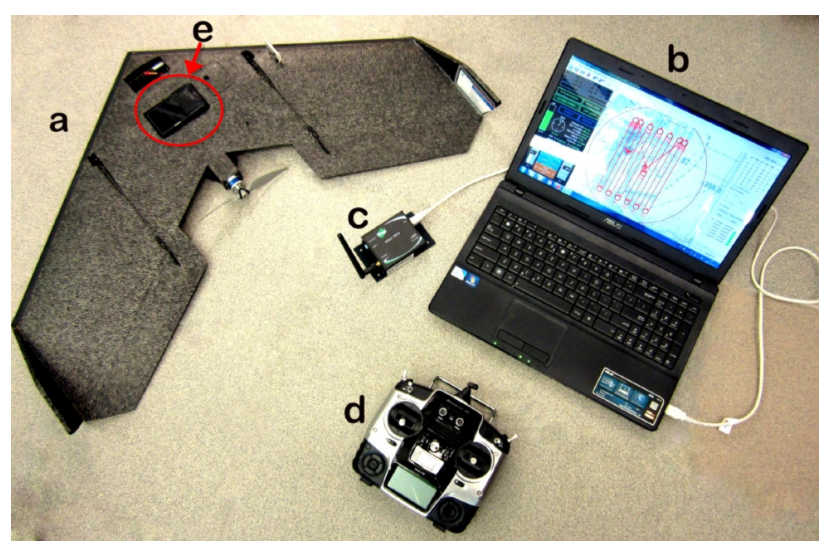

Fig. 1. Swinglet CAM system comprising: (a) unmanned aerial vehicle (UAV), (b) ground control station, (c) radiomodem, (d) remote control, (e) camera 
Table 1. Weather conditions during example flooding situations in the study site of Krosnowice

\begin{tabular}{|c|c|c|c|}
\hline \multicolumn{4}{|c|}{ KROSNOWICE gauge (warning state: $170 \mathrm{~cm}$, emergency state $220 \mathrm{~cm}$ ) } \\
\hline & $\begin{array}{l}\text { Beginning of flooding } \\
\text { exceedence of warning state }\end{array}$ & $\begin{array}{l}\text { Possibility of flight } \\
\text { according to weater conditions }\end{array}$ & $\begin{array}{c}\text { Possibility of flight } \\
\text { according to legal cinditions }\end{array}$ \\
\hline \multicolumn{4}{|l|}{ Situation A } \\
\hline date & 11/05/2013, 20:30 UTC & 12/05/2013, 16:16 UTC & 13/05/2013, 06:00 UTC \\
\hline water level & $170.1 \mathrm{~cm}$ & $197.6 \mathrm{~cm}$ & $175.0 \mathrm{~cm}$ \\
\hline precipitation $^{3}$ & $0.2 \mathrm{~mm}$ & $0 \mathrm{~mm}$ & $0 \mathrm{~mm}$ \\
\hline wind speed ${ }^{3}$ & $1.1 \mathrm{~m} / \mathrm{s}$ & $0 \mathrm{~m} / \mathrm{s}$ & $0 \mathrm{~m} / \mathrm{s}$ \\
\hline \multicolumn{4}{|l|}{ Situation B } \\
\hline date & 14/09/2013, 07:53 UTC & 14/09/2013, 15:02 UTC & 15/09/2013, 06:00 UTC \\
\hline water level & $175.3 \mathrm{~cm}$ & $213.5 \mathrm{~cm}$ & $180.1 \mathrm{~cm}$ \\
\hline precipitation $^{3}$ & $1.6 \mathrm{~mm}$ & $0 \mathrm{~mm}$ & $0 \mathrm{~mm}$ \\
\hline wind speed ${ }^{3}$ & $0.6 \mathrm{~m} / \mathrm{s}$ & $0.6 \mathrm{~m} / \mathrm{s}$ & $0.6 \mathrm{~m} / \mathrm{s}$ \\
\hline
\end{tabular}

${ }^{1}$ The first moment when both conditions: wind speed $<7 \mathrm{~m} / \mathrm{s}$ and precipitation $=0$ are fulfilled.

${ }^{2}$ If Polish Air Navigation Services Agency issues a long term reservation of airspace, Airspace Request Message (RQA) must be submitted one day in advance before scheduled flights, thus not later than 10:00 UTC on an applica-tion day in order to perform the flights on the next day (flights possible from 6:00 UTC). In the case of Situation A, RQA must be submitted after hydrologic warning is predicted (water level $>170 \mathrm{~cm}$ ), hence from $20: 30$ UTC on 11/05/2013 but not later than 10:00 UTC on 12/05/2013 (flight possible at 06:00 UTC on 13/05/2013). In the case of Situation B, RQA must be submitted after hydrologic warning is predicted (water level > $170 \mathrm{~cm}$ ), hence from 07:53 UTC on 14/09/2013 but not later than 10:00 UTC on 14/09/2013 (flight possible at 06:00 UTC on 15/09/2013).

${ }^{3}$ Parameters taken from the nearest weather station, Kłodzko (approximately $6 \mathrm{~km}$ from the study site).

automatic systems fail, the autopilot can be overruled by a remote control (Fig. 1d) operated by an experienced person. The typical flight speed, when the UAV is airborne, is approximately equal to $10 \mathrm{~m} / \mathrm{s}$, while the climbing speed rate is around $3 \mathrm{~m} / \mathrm{s}$. It is not advisable to perform missions in rain or snow, however the specification allows missions in foggy and windy conditions, as long as wind speed does not exceed $7 \mathrm{~m} / \mathrm{s}$. Flying upwind reduces the UAV speed, and side winds intensify rolling of the UAV. Surveying can be carried out regardless of wind direction. The best quality images are captured on sunny days, preferably with no wind.

Weather conditions during periods of flooding can be unsuitable for UAV flights. However, the actual meteorological parameters for the study area juxtaposed in Table 1 prove that flights can be carried out, and inundation can be detected, even with the delays enforced by the weather and legal restrictions. The ground station uses a radiomodem to provide a data link, and aerial photos are ready for further processing as soon as the UAV has landed.

\subsection{Photogrammetry from close range oblique aerial imagery}

All cameras acquire data without making physical contact with the source, which makes them, according to definition (Paine, Kiser 2003), remote sensors. Photogrammetry uses aerial photos to obtain reliable quantitative information, i.e. measurements (Slama 1980). Traditional aerial photogrammetry, using vertical images (with the axis of a camera inclined no more than 3 from a vertical plane), serves as a great source of spatial information, but is cost-effective only for large areas. The need for spatial data, and also the increasingly easy access to hand-held high resolution consumer cameras, contributed to the de- velopment of a new image acquisition process - close range (low) oblique aerial imagery (Fig. 2).

In order to apply the procedures of photogrammetric image processing to oblique photos from consumer cameras, unique features have to be considered (Grenzdörffer et al. 2008), namely:

- varying scales due to zoom options,

- no fixed focal length,

- minimum exposure intervals,

- external storage capacity,

- mechanical stability of the sensor (interior orientation),

- temporal eccentricity (exposure delay).

Procedures used for geometric and radiometric calibration of the camera, and also the setting of the zoom to a constant level, helped to generate a modified workflow for generating the geometrically corrected materials.

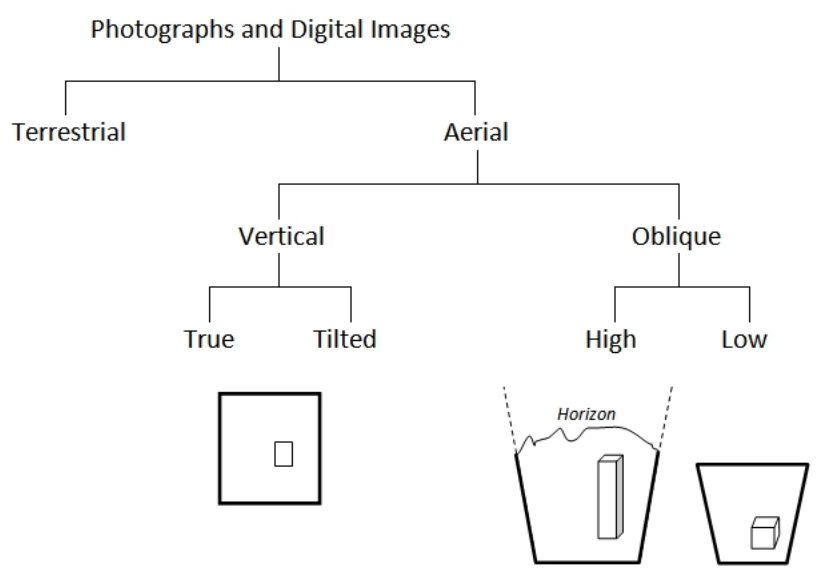

Fig. 2. Classification of aerial photographs and digital images with the relative size and shape of ground area photographed from three different angles (after Paine and Kieser 2003, modified) 


\subsection{Orthophotos as research material}

Aerial photos are a great source of spatial data. However, topographic displacement, tilt, and sometimes camera lens distortion, make their geometry ineligible for quantitative measurements. In order to change the perspective projection of a photo to the orthographic position, a process of orthorectification needs to be executed. The final product ensures geometric correctness and enables an orthoimage to be treated as cartometric material. Highresolution orthophotos are used for the acquisition of topographic information, navigation and visualization, and can thus serve not only as basic tools for base mapping, but have endless possibilities in the research of various features in environmental studies, as well as in other sciences. Mikuni (1996) stated that digital orthophotography is "rapidly becoming one of the most universally useable Mapping and Remote Sensing Tools for the 21st century". Almost 20 years later, there is no doubt that his words have been confirmed, as may be inferred from multiple publications. For instance, Vassilopoulou et al. (2002) monitored volcanic hazards using orthophotos, while Somodi et al. (2012) used them for the recognition of invasive species. An engineering orthophoto application is represented by Larsson and Nilsson (2005), who determined the costs of preparing abandoned farmland for the cultivation of energy crops. Niethammer et al. (2012), through their landslide analysis, showed a possible use of ortorectified photos for geological research. It is not only technical and natural sciences that benefit from ortophotomaps - there are, for instance, multiple studies based on orthoimages in archaeology (e.g. Chiabrando et al. 2011; Verhoeven et al. 2012).

\subsection{The use of orthophotomaps in hydrological studies}

Aerial photography and image interpretation are commonly used in the scrutinising of the spatial effects of floods. Photos taken from the air are, as representations of terrain surface, sources of accurate information about the extent of flooding and flood wave propagation (Bates, De Roo 2000; Kasprzak, Migoń 2010). Of particular importance here is the opportunity for the observation of morphometric changes of various morphological forms provided by images obtained at specific regular intervals. They enable the determination of the influence of particular phenomena on landforms, and also a view of their changes through time. In the context of investigating terrain surface, it is worth giving an example - aerial photographs are used for to delimit river channel patterns and for monitoring accumulation and erosion forms (Marcus, Fonstad 2008). For terrain analysis the use of stereo-pair images is possible. They enable the identification of morphological forms that are invisible from the surface (e.g. palaeochannels). Currently, however, the analysis of highresolution digital elevation models is usually used instead of this method (Tarboton et al. 2006; Kasprzak, Migoń 2010). Fluvial forms can also be inferred in small scale from otrhophotomaps - such analysis was carried out on the basis of satellite imagery (Landsat) produced by NASA (National Aeronautics and Space Administration) and the USGS (United States Geological Survey). The need for the morphometric examination of small fluvial forms triggered the search for techniques for taking aerial photos which are very often at resolutions higher than those offered by satellites. Airborne remote sensing, i.e. unmanned balloons, airplanes and helicopters, provided a solution here. Shaw et al. (2011) emphasise the potential of airborne remote sensing with regard to hydrological understanding of the environment, especially where traditional data collection is difficult or impossible.

It should be emphasised that all photos taken by airborne sensors are oblique and contain distortion that requires further processing in order to obtain othophotomaps for morphometric analysis. Another restriction connected to the use of the UAV in hydrological studies is raised by Shaw et al. (2011), who claim that UAVs are unable to penetrate the water surface (thus no data on channel crosssection geometry).

\subsection{Orthophotomap generation - workflow}

The aim of the orthorectification process is to eliminate the perspective of the image. Pictures taken by a camera depict - just like the human eye - the perspective view of the world, i.e. an image is projected through a perspective centre onto an image plane (Nielsen 2004). In the case of aerial photography, this causes the impression that higher objects (those closer to the camera) are relatively larger than objects located lower. The final product of othorectification is an image in orthographic projection, with the rays parallel (instead of rays passing a common perspective centre in the perspective projection of raw photo). Thus, an orthophotomap has a consistent scale and can be used as a planimetric map.

In analogue and digital images, the orthophoto generation procedures have the same geometrical principles, but the workflow differs due to the use of tools and techniques that are markedly different. The variety of photogrammetric software makes the orthophoto generation process possible. Analogue and digital images differ in complexity and targeted customer groups, but Vallet et al. (2011) name common elements that comprise the output data:

(1) camera calibration parameters,

(2) Bundle adjustment results: estimated tie point coordinates,

(3) DTM or digital surface model (DSM),

(4) orthomosaic.

The procedure for obtaining these results will be briefly explained below.

In consumer grade cameras used in UAVs, inertial orientation parameters are neither known nor stable (Turner et al. 2012). In order to solve the problem of the interior orientation of the camera, as well as the exterior orientation of each individual photo, the procedure introduced by 
Wolf and Dewitt (2000) needs to be employed. This process, called the Bundle Block Adjustment, uses the GPS and IMU modules to initially estimate camera pose and then match images in datasets (Bryson et al. 2010), but due to the high inaccuracy of GPS and IMU in the UAV sensors another algorithm is also used to detect tie/pass points and complete the Bundle Block Adjustment (Dandois, Ellis 2010) with final products (1) and (2). Building the geometry of a 3D model is a computationally intensive operation, but it is necessary for the generation of a DSM (3), as well as an orthophoto. The final orthophoto is rectified based on locations acquired in the Bundle Block Adjustment and can be mosaicked into one single orthomosaic (4) that covers the entire study area. The ground control points, the coordinates of which should be precisely measured using geodetic techniques, ought to be incorporated into the orthophoto image generation procedure. However, the materials presented in this paper are produced without taking them into account, as the objective is to offer a feasibility study that shows the potential of UAVacquired photos in the enhancing of real-time inundation prediction experiments.

\section{Study area}

Kłodzko County is located in the Central and Eastern Sudetes, in South-Western Poland. The main river of the region is Nysa Kłodzka, and its key tributaries include the following rivers: Ścinawka, Bystrzyca Dusznicka, Bystrzyca Łomnicka, Wilczka and Biała Lądecka with Morawka. Almost the entire area belongs to the basin of the Odra River (Fig. 3). Unique topographical conditions are found in a large mid-mountain abasement of the Kłodzko Valley, which occupies almost the entire area of the county. This topography and the extensive hydrographic network con-

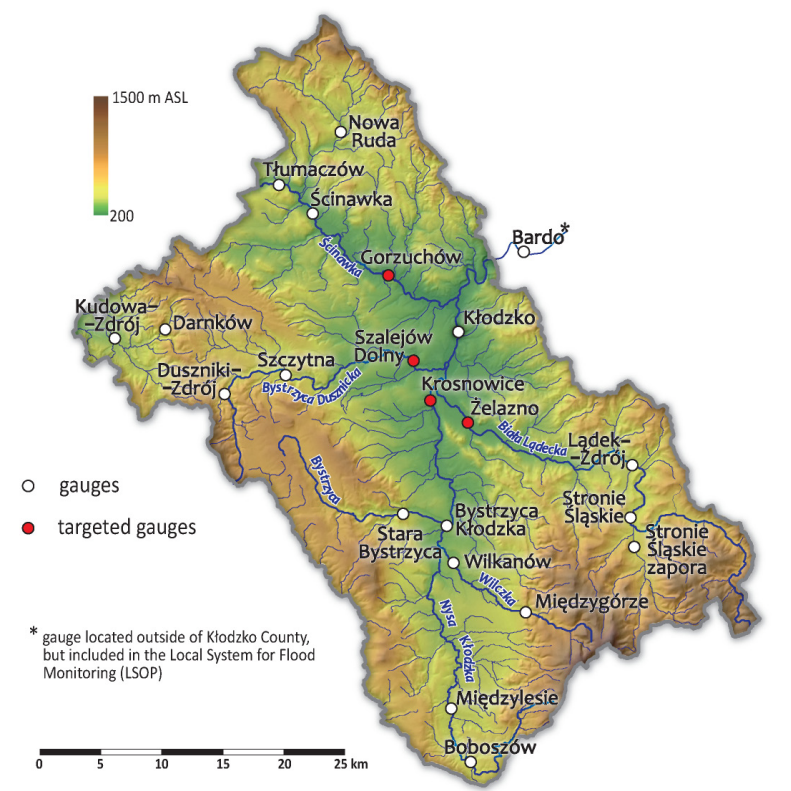

Fig. 3. Gauges of the Local System for Flood Monitoring (in Polish: LSOP - Lokalny System Osłony Przeciwpowodziowej) in Kłodzko County, SW Poland tribute to rapid and catastrophic floods that have plagued residents of the county. Prevailing conditions, such as sudden and rapid changes in water levels and discharges of mountain streams and rivers, significantly limit the ability to counteract the effects of a flood, and additionally make early warning and evacuation of people difficult.

The flood hazard ratio used by the Institute of Meteorology and Water Management in Poland (IMGW), and calculated separately for each gauge profile, shows that Kłodzko County is particularly vulnerable to the occurrence of disastrous floods (Dubicki et al. 2005). The flood hazard ratio for water gauges located in this area is among the highest in the Dolnośląskie Voivodeship, with the top values ranging between 0.942 and 0.986 for the gauges: Międzylesie, Lądek-Zdrój, Żelazno, Szalejów Dolny, Kłodzko and Gorzuchów (values adopted from Dubicki et al. 2005). The predominant type of floods, which occur in July and August, are summer rain-induced floods (Dubicki et al. 2005).

The above-mentioned catastrophic character of floods was one of the main factors that led to the creation of the Local System for Flood Monitoring (in Polish: Lokalny System Osłony Przeciwpowodziowej-LSOP, see Fig. 3 for the location of hydrologic gauges). The system was launched by the local authorities in April 2002 and since that time has been providing citizens with valuable and up-to-date information on riverflow, measured in real-time at multiple hydrologic gauges. At present the system consists of:

- 22 automatic gauges at which water levels are measured,

- 18 automatic rain gauges,

- a dispatcher position in the District Crisis Management Centre,

- 14 posts dispatching centres within the Municipal Emergency Management.

The data recorded by the LSOP are transmitted every 15 minutes to emergency services, inspections, guards and the website, which is updated in real-time. The project researchers started a successful cooperation and partnership with the County Office in Kłodzko and its authorities, and access to water level readings and precipitation data was provided for research purposes. This integration of science and emergency management services gives new possibilities for the increased security of county residents in the future.

\section{Results}

The aim of this study was to determine the potential for unmanned aerial systems to be used for the verification of spatial flood predictions. Overall, the results of the exercise can be divided into two parts:

- extensive analysis of the hydrologic network, flood hazard and topographic conditions, and the resulting selection of gauges for which inundation predictions will be calculated and for which the UAV flight missions are desired, 
- a number of test missions with the swinglet CAM, targeted at the selected LSOP gauges and the areas downstream and upstream of those sites, with the subsequent processing of imagery.

\subsection{Selection of gauges and targeted areas for flight missions}

The selection of hydrologic gauges, at which spatial prognosis as well as its aerial verification should be performed in near-real-time, was based on the following two factors: (1) our inference regarding sites where reasonable hydrograph prognosis is feasible, (2) our scrutiny regarding where the spatial prediction of overbank flow may serve as a true warning for inhabitants.

The HydroProg system will produce hydrograph prognoses for the following gauges:

- Bardo, Kłodzko, Krosnowice, Bystrzyca Kłodzka, Międzylesie (the Nysa Kłodzka River),

- Żelazno, Lądek-Zdrój (the Biała Lądecka River),

- Gorzuchów, Ścinawka Górna (the Ścinawka River),

- Szalejów Dolny, Szczytna (the Bystrzyca Dusznicka River).

Fig. 3 presents these against the background of all the hydrologic gauges and rain gauges of the LSOP.

During the time of the publication of this article, regular test flights in the vicinity of four gauges (Gorzuchów, Szalejów Dolny, Żelazno and Krosnowice) have commenced (Fig. 3). During the flight planning procedure, multiple decisions about flight parameters need to be made. Numerous values, which are entered into the flight-planning software, depend on: targeted spatial resolution, weather conditions, topography, flight duration, size of targeted area and legal issues.

The light weight of the swinglet CAM results in its extreme vulnerability to exterior conditions, thus the parameters obtained during flights are variable and strongly weather-dependent. The relationship between pre-set and obtained parameters during the test flights are shown in Table 2 .

\subsection{New high-resolution orthophotomaps}

Following the procedure described in section 2.5 we produced 8 orthophotomaps and 8 DSMs, and in the production process we used raw data acquired during 8 missions over the areas adjacent to the gauges in Szalejów Dolny, Gorzuchów and Żelazno. Hereinafter, we present the final products as well as the obtained parameters of two flights in the vicinity of the gauge in Szalejów Dolny on $27 / 11 / 2012$ and $08 / 01 / 2013$. We have chosen these two for presentation because they can serve to prove the possibility of frequent observations over the selected area, comparability of the acquired data, and identification of possible spatial changes in the environment.

The sub-products of the orthophoto generation and their specifications (see section 2.5) are the following:

- Camera parameters (the same camera and the UAV were used in both flight missions);

- Bundle Block Adjustment;

- Orthophotomap,

For each flight survey a separate ortophoto was generated based on aligned chunks of photos, the locations of which, and their overlap, is presented in Fig. 4. Boundaries have been set in order to cut out the edges where side overlap is not sufficient. In the case of narrow mountainous rivers, which we focus on, providing detailed spatial information is crucial for the detection of small changes of inundation, thus the targeted resolution chosen was the highest available. Both orthophotomaps reveal a remarkable resolution of almost $3 \mathrm{~cm} /$ pix, but the lack of ground control points introduces a location error (shift). In the spatially extended fragments (Fig. 5), we can observe that even small changes in the river channel and in its vicinity can be detected in an orthophoto. Not only snow cover surface features are visible, but even side point bars under the surface can be observed. Changes in the water level can also be detected using the UAV. This is presented in Fig. 6 which compares orthophotomaps generated in Gorzuchów during low and high water stages of the Ścinawa River, as recorded by the swinglet CAM in 2012 and 2013;

Table 2. Pre-set and obtained flight parameters - summary of research flights over three study areas (Gorzuchów, Szalejów Dolny, Żelazno) on 27/11/2012 and 08/01/2013

\begin{tabular}{|c|c|c|c|c|c|c|c|c|c|c|c|c|}
\hline \multirow[b]{2}{*}{ Date } & \multirow[b]{2}{*}{ Targeted gauge } & \multicolumn{3}{|c|}{ Pre-set parameters } & \multicolumn{8}{|c|}{ Obtained parameters } \\
\hline & & 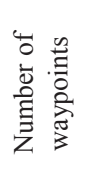 & 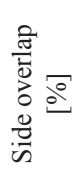 & 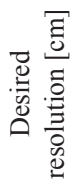 & 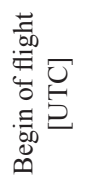 & 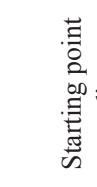 & $\begin{array}{l}\text { 떠 } \\
\text { 진 }\end{array}$ & 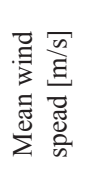 & 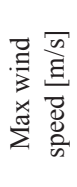 & 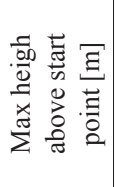 & 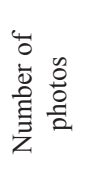 & 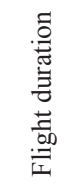 \\
\hline \multirow[t]{4}{*}{$27 / 11 / 2012$} & Gorzuchów & 8 & 60 & 4 & 09:18 & 50.484 & 16.569 & 1.62 & 2.32 & 113.64 & 123 & $15: 01$ \\
\hline & Gorzuchów & 9 & 60 & 4 & 09:53 & 50.484 & 16.569 & 1.43 & 2.05 & 112.35 & 145 & $17: 22$ \\
\hline & Szalejów Dolny & 13 & 60 & 4 & 11:03 & 50.421 & 16.606 & 4.38 & 5.87 & 115.44 & 230 & $30: 06$ \\
\hline & Żelazno & 13 & 60 & 4 & $13: 08$ & 50.368 & 16.668 & 4.22 & 5.23 & 113.60 & 98 & $15: 35$ \\
\hline \multirow[t]{2}{*}{ 08/01/2013 } & Gorzuchów & 8 & 60 & 3 & 09:13 & 50.484 & 16.569 & 0.61 & 1.60 & 89.45 & 62 & 10:02 \\
\hline & Szalejów Dolny & 13 & 60 & 4 & $11: 19$ & 50.421 & 16.607 & 2.92 & 3.89 & 113.77 & 207 & $23: 32$ \\
\hline
\end{tabular}



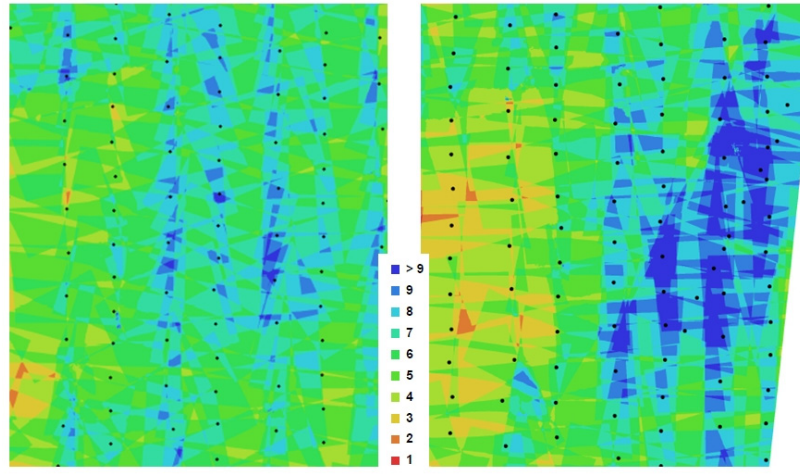

Fig. 4. Estimated camera locations (marked with black dots) and image overlap (shown with color scale) recorded during two flights over the study area in Szalejów Dolny: 27/11/2012 (left), 08/01/2013 (right)
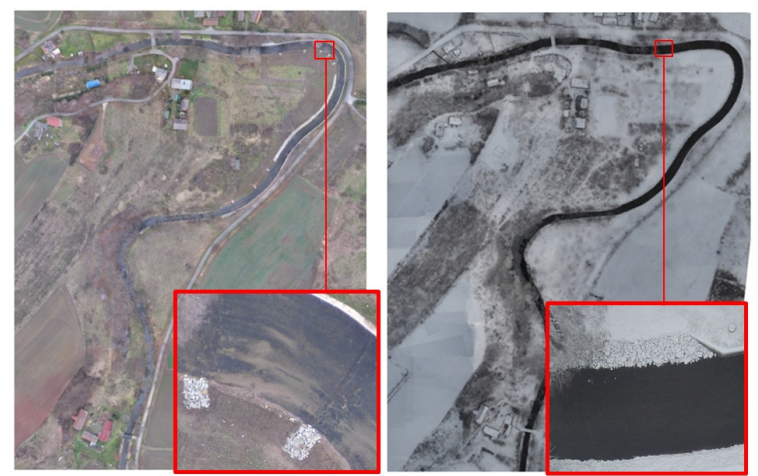

Fig. 5. Generated orthophotomaps of the study area in Szalejów Dolny, two different fragments located along the river are enlarged to show resolution: 27/11/2012 (left), 08/01/2013 (right)
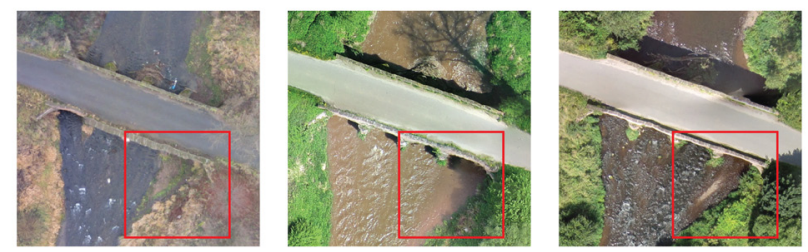

Fig. 6. Orthophotos capturing different water levels in Gorzuchów (near the bridge in the vicinity of the hydrologic gauge) on 27/11/2012 (left), 13/05/2013 (middle) - during warning stage, 21/08/2013 (right)
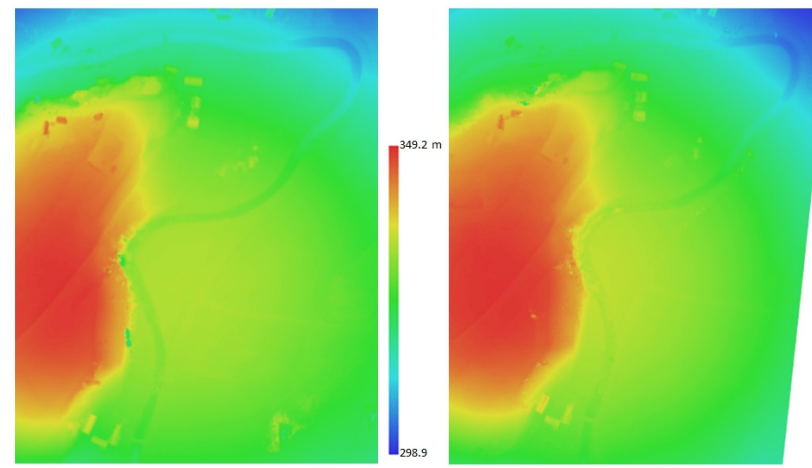

Fig. 7. Reconstructed Digital Surface Models of the study area in Szalejów Dolny, with resolution of $11.44 \mathrm{~cm} /$ pix, point density of 65.44 points/m: 27/11/2012 (left), 08/01/2013 (right)

\section{- Digital Surface Model,}

The aim of the experiment was not to generate a DSM (Fig. 7), but it has been released as a side product of the
Bundle Block Adjustment and it demonstrates a high resolution of $11 \mathrm{~cm} /$ pix. Although the relative position of height fields is accurate, the model maintains considerable location errors, mainly in the height parameter. This may be fixed by including the ground control points in the procedure for generating DSM, which will enable the model to be placed in appropriate location with respect to the WGS84 ellipsoid.

\section{Concluding remark and further research}

The unmanned aerial vehicle allows us to acquire high temporal and spatial resolution data, which is appropriate for hydrologic analysis. Its advantages are: flexibility in deployment, low cost surveys, and the short time required for the arrangement of a mission (and quick reaction if needed), and spectacularly high resolution of up to $3 \mathrm{~cm} /$ pix. However, there are also disadvantages that may hamper investigations into the verification of hydrologic predictions, namely: strong dependency on weather conditions, the requirement of postflight image processing in order to make the final product cartometric and free of geometric distortions. The UAV-based remote sensing fills the gap between high-cost and time-consuming terrestrial measurements and high-cost and high-range aerial photo acquisition, which in fact also provides lower resolution products.

During the experimental UAV missions carried out in the vicinity of three gauges of the Local System of Flood Monitoring in Kłodzko County, we were given the opportunity to test the feasibility of our concept of aerial verification of flood inundation predictions. For further operational flights we have chosen precise take-off and landing sites, available over the entire year, so that there is no need for the analysis of maps or the surveying of terrain when the real-time aerial verification module should be switched on in real-time. All flights accomplished at those three study areas were fully successful. We corrected the flight plans and produced the ultimate ones so that the real-time execution of the mission, when aerial verification of forecasts is needed, becomes straightforward. Finally, from the raw materials acquired by the UAV, we produced high-resolution orthoimages, the level of detail of which clearly confirms that they may be utilised for monitoring overbank flow episodes. A deeper insight into the generated orthoimages allows us to observe that the attained resolution is good enough to carry out advanced analyses of fluvial systems, both from the hydrologic and geomorphological perspectives.

Given the above concluding remarks, further research should focus on:

- carrying out additional surveys during periods of flood risk,

- evaluating the quality of the orthophoto images and DSMs,

- automation of flood warnings sent by email to the UAV operating team so that they are able to immediately or- 
ganise field trips and conduct multiple aerial missions in the vicinity of the selected gauges.

\section{Acknowledgements}

The research was financed by the National Science Centre in Poland through the grant no. 2011/01/D/ ST10/04171 under the leadership of Dr hab. Prof. Tomasz Niedzielski. The UAV equipment was acquired from the statutory funds of the Institute of Geography and Regional Development of the University of Wrocław, Poland. The authors would like to acknowledge the authorities of the County Office in Kłodzko for productive collaboration in our research project and for making the gauges of the Local Flood Monitoring System accessible for scientific purposes. We would also like to mention the courtesy of the Polish Air Navigation Services Agency, which was always helpful with the issuing of permits for our surveys. Last, but not least, we thank the anonymous reviewer who offered us valuable remarks that led to the improvement of the paper.

\section{Bibliography}

Bates P.D., 2004, Remote sensing and flood inundation modelling, Hydrological Processes 18 (13), 2593-2597. DOI: 10.1002/hyp.5649

Bates P.D, De Roo A.P.J., 2000, A simple raster-based model for flood inundation simulation, Journal of Hydrology, 236 (1-2), 54-77

Bryson M., Reid A., Ramos F., Sukkarieh S., 2010, Airborne vision-based mapping and classification of large farmland environments, Journal of Field Robotics, 27 (5), 632-655, DOI: $10.1002 /$ rob. 20343

Butts M., Dubicki A., Strońska K., Jørgensen G., Nalberczyński A., Lewandowski A., Van Kalken T., 2007, Flood forecasting for the upper and middle Odra River basin, [in:] Flood Risk Management in Europe, S. Begum, M.J.F. Stive, J.W. Hall (eds.), Springer, 353-384

Chiabrando F., Nex F., Piatti D., Rinaudo F., 2011, UAV and RPV systems for photogrammetric surveys in archaeological areas: two tests in the Piedmont region (Italy), Journal of Archaeological Science, 38 (3), 697-710, DOI: 10.1016/j. jas.2010.10.022

Cloke H.L., Pappenberger F., 2009, Ensemble flood forecasting: A review, Journal of Hydrology, 375 (3), 613-626

Dandois J.P., Ellis E.C., 2010, Remote sensing of vegetation structure using computer vision, Remote Sensing, 2 (4), 1157-1176, DOI: 10.3390/rs2041157

Dubicki A., Radczuk L., Adynkiewicz-Piragas M., Tokarczyk T., Mordalska H., Maciejowska B., Lisowski J., Bogusz A., Krzyścin K., 2005, Wody powierzchniowe, [in:] Opracowanie ekofizjograficzne dla województwa dolnośląskiego z załącznikami, Wojewódzkie Biuro Urbanistyczne we Wrocławiu, 79-92

Eisenbeiss H., Lambers K., Sauerbier M., 2007, Photogrammetric recording of the archaeological site of Pinchango Alto (Palpa, Peru) using a mini helicopter (UAV), [in:] Pro- ceedings of the 33rd CAA Conference, Tomar, Portugal, A. Figueiredo (ed.), 175-184

Franz K., Ajami N., Schaake J., Buizza R., 2005, Hydrologic ensemble prediction experiment focuses on reliable forecasts, Eos, 86 (25), 239, DOI: 10.1029/2005EO250004

Grenzdörfer G.J., Guretzki M., Friedlander I., 2008, Photogrammetric image acquisition and image analysis of oblique imagery, Photogrammetric Record, 23(124), 372-386

Horritt M.S., Bates P.D., 2002, Evaluation of 1D and 2D numerical models for predicting river flood inundation, Journal of Hydrology, 268 (1-4), 87-99

Kasprzak M., Migoń P., 2010, Prognozowanie geomorfologicznych skutków wezbrań i powodzi, [in:] Wyjątkowe zdarzenia przyrodnicze na Dolnym Śląsku i ich skutki, P. Migoń (ed.), Rozprawy Naukowe Instytutu Geografii i Rozwoju Regionalnego Uniwersytetu Wrocławskiego, 14, 269-290

Küng O., Strecha C., Beyeler A., Zufferey J.C., Floreano D., Fua P., Gervaix F., 2011, The accuracy of automatic photogrammetric techniques on ultra-light UAV imagery, International Archives of the Photogrammetry, Remote Sensing and Spatial Information Sciences, XXXVIII-1/C2, 125-130

Larsson S., Nilsson C., 2005, A remote sensing methodology to assess the costs of preparing abandoned farmland for energy crop cultivation in northern Sweden, Biomass and Bioenergy, $28,1-6$

Marcus W.A., Fonstad M.A., 2008, Optical remote mapping of rivers at sub-meter resolution and watershed extents, Earth Surface Processes and Landforms, 33 (1), 4-24, DOI: 10.1002/esp.1637

Merwade V., Cook A., Coonrod J., 2008, GIS techniques for creating river terrain models for hydrodynamic modelling and flood inundation mapping, Environmental Modelling \& Software, 23 (10-11), 1300-1311

Mikuni A.M., 1996, Digital Orthophoto Production, [in:] Digital Photogrammetry - An Addendum to the Manual of Photogrammetry, C. Greve (ed.), Bethesda, MD: American Society of Photogrammetry

Nielsen M.O., 2004, True orthophoto generation (Masters Thesis) Niethammer U., James M.R., Rothmund S., Travelletti J., Joswig M., 2012, UAV-based remote sensing of the Super-Sauze landslide: Evaluation and results, Engineering Geology, 128 (1), 2-11, DOI: 10.1016/j.enggeo. 2011.03.012

Paine D., Kiser J., 2003, Aerial Photography and Image Interpretation, 2nd ed. John Wiley \& Sons Inc., Hoboken, New Jersey

Przybilla H.J., Wester-Ebbinghaus W., 1979, Bildflug mit ferngelenktem Kleinflugzeug. Bildmessung und Luftbildwesen, Zeitschrift fuer Photogrammetrie und Fernerkundung, 47, 137-14

Sanders B.F., 2007, Evaluation of on-line DEMs for flood inundation modelling, Advances in Water Resources, 30, 18311843, DOI: 10.1016/j.advwatres.2007.02.005

Schaake J., Franz K., Bradley A., Buizza R., 2006, The Hydrologic Ensemble Prediction EXperiment (HEPEX), Hydrology and Earth System Sciences Discussions, 3, 3321-3332, DOI: 10.5194/hessd-3-3321-2006

Schumann G., Matgen P., Cutler M.E.J., Black A., Hoffmann L., Pfister L., 2008, Comparison of remotely sensed water stages 
from LiDAR, topographic contours and SRTM, ISPRS Journal of Photogrammetry and Remote Sensing, 63 (3), 283-296

Shaw E.M., Beven K.J., Chappell N.A., Lamb R., 2011, Hydrology in Practice, Fourth Edition, Spon, London

Slama C. (ed.), 1980, Manual of Photogrammetry, American Society of Photogrammetry, Falls Church, VA

Somodi I., Carni A., Ribeiro D., Podobnikar T., 2012, Recognition of the invasive species Robinia pseudacacia from combined remote sensing and GIS sources, Biological Conservation, 150 (1), 59-67, DOI: 10.1016/j.biocon.2012.02.014

Tarboton D.G., Bras R.L., Rodriguez-Iturbe I., 2006, On the extraction of channel networks from digital elevation data, Hydrological Processes, Special Issue: Digital Terrain Modelling in Hydrology, 5 (1), 81-100, DOI: 10.1002/hyp.3360050107

Turner D., Lucieer A., Watson C., 2012, An Automated Technique for Generating Georectified Mosaics from Ultra-High Resolution Unmanned Aerial Vehicle (UAV) Imagery, Based on Structure from Motion (SfM) Point Clouds, Remote Sensing, 4 (5), 1392-1410, DOI: 10.3390/rs4051392

Vallet J., Panissod F., Strecha C., Tracol M., 2011, Photogrammetric Performance of an Ultra Light Weight swinglet "UAV", International Conference on Unmanned Aerial
Vehicle in Geomatics (UAV-g), 14-16 September, Zurich, Switzerland, SPRS Archives, XXXVIII-1/C22, 253-258

Vassilopoulou S., Hurni L., Dietrich V., Baltsavias E., Pateraki M., Lagios E., Parcharidis I., 2002, Orthophoto generation using IKONOS imagery and high-resolution DEM: a case study on volcanic hazard monitoring of Nisyros Island (Greece), ISPRS Journal of Photogrammetry and Remote Sensing, 57 (1), 24-38, DOI: 10.1016/S0924-2716(02)00126-0

Verhoeven G., Doneus M., Briese C., Vermeulen F., 2012, Mapping by matching - A computer vision-based approach to fast and accurate georeferencing of archaeological aerial photographs, Journal of Archaeological Science, 39, 2060-2070

Wolf P.R., Dewitt B.A., 2000, Elements of Photogrammetry with Applications in GIS, 3rd ed., McGraw-Hill, New York

Zappa M., Rotach M.W., Arpagaus M., Dorninger M., Hegg C., Montani A., Ranzi R., Ament F., Germann U., Grossi G., Jaun S., Rossa A., Vogt S., Walser A., Wehrhahn J., Wunram C., 2008, MAP D-PHASE: real-time demonstration of hydrological ensemble prediction systems, Atmospheric Science Letters, 9, 80-87 
